\title{
Incomplete cost - incomplete benefit analysis in transport appraisal
}

\author{
Robin Hickman and Marco Dean \\ Bartlett School of Planning, University College London, UK
}

Transport Reviews, 2017

DOI: 10.1080/01441647.2017.1407377

\begin{abstract}
This paper examines the current application of transport appraisal in the UK, in particular exploring the partiality of cost-benefit analysis (CBA) within the wider multi-criteria analysis (MCA) process. It argues that applying a quantitative assessment of the varied impacts of complex transport projects can only be partial within the CBA. Analysis can overlook social, human life, environmental and built environment impacts, and projects can be inconsistent with the planning strategy for an area.
\end{abstract}

The application of CBA is critically reviewed using two case studies: the proposed upgrade of the South Fylde railway line and the Heysham-M6 Link Road, both from North West England. A participatory MCA process is suggested to help improve the process of transport appraisal, as part of an improved public debate on transport investment priorities.

\section{Introduction}

Transport appraisal involves making choices between different projects and funding allocations deciding which projects, and of what form, might be the best spend of money. The decision-making process can be complex, including estimating likely impacts of proposed projects across multiple and sometimes competing goals, and assessing how projects might best support urban planning objectives. Different approaches are used to appraise projects, and there are often a suite of studies that make up the overall appraisal. Within the UK, the Green Book (HM Treasury, 2003) sets the basis for project appraisal. Extensive guidance is given to practitioners via the Website for Transport Analysis Guidance (WebTAG) (Department for Transport, 2017). Project options are first examined and assessed against the five cases - Strategic, Economic, Commercial, Financial and Management. The best performing options are subject to more detailed appraisal and a final option(s) is usually taken forward for implementation. Multi-criteria analysis (MCA) forms the basis of transport appraisal and cost-benefit analysis (CBA) is an important part of this, particularly in the economic case. The Business Case is seen as the five cases considered together and the Appraisal Summary Table (AST) summarises the analysis. The appraisal is usually carried out ex-ante (before the fact), comparing the difference between the 'without project' and 'with project' cases.

CBA is known more accurately as social CBA when applied in relation to governmental investment, i.e. where private costs and benefits are replaced by societal costs and benefits. CBA is rooted in Welfare Economics (which uses microeconomic techniques to measure well-being at the aggregate level) and is based on the notion of the rational individual, where a person makes decisions on the basis of known costs and benefits. CBA is described as a practical way of assessing the desirability of projects, involving the enumeration of: "all the relevant costs and benefits" (Prest and Turvey, 1965, p.683). There is wide divergence in views on the use of CBA - it has "fearless champions and resolute detractors" (Sen, 2000, p.931). There have been a number of reviews, including highlighting the potential sources of error and bias in project appraisal (Mackie and Preston, 1998). It is widely acknowledged that CBA has many potential problems in application and is sometimes flawed; but that it remains a useful decision-making procedure, superior to alternative approaches (Posner and Adler, 1999). A perceived strength is that CBA allows value judgements to be made explicitly (Brent, 2006). Comparisons are made relative to a previous time of 'pork-barrel politics', where funding was obtained to finance projects benefiting particular constituents and with little transparency. A formalised process means that projects are funded against clearer criteria. For the more forthright 
advocates, CBA is viewed as providing "much of the information needed when making decisions about whether to approve an investment and how it might rank when compared with other transport schemes competing for limited funds" (Worsley, 2014, p.17); a "framework within which impacts are quantified on a consistent basis, forcing decision makers to face up to numbers" (Mackie et al., 2014, p.4); and, even, an example of "decision-making by democratic consent" (Mackie et al., 2014, p.3). The current transport appraisal process is put forward as rational, transparent and objective, providing a useful analytical framework for decision-making (Worsley and Mackie, 2015).

But, alongside, there is a much more critical debate, with concerns that the final benefit-cost ratios $(B C R)$, and prioritisation of resources through $C B A$, significantly depend on the assumptions taken and application of the framework. Kornhauser (2000, p.1037), for example, maintains that its "justificatory foundations remain at best suspect and at worst in ruins". Others suggest CBA is unsuited to prioritising investment in public policy (Neuburger and Fraser, 1993, Ackerman and Heinzerling, 2004, Ackerman, 2008) - including investment in transport projects (such as Self, 1970, Adams, 1994, Næss, 2006, Dimitriou et al., 2012, Næss, 2016).

The contribution of this paper is to critically review some of the voluminous literature concerning the use of CBA in project appraisal, from the perspective of attempting to make the case for investment in public transport in North West England. It focuses, in particular, on the potential for partiality in the process. Two case studies are used to illustrate the issues found in practice: the proposed upgrade of the South Fylde railway line and the Heysham-M6 Link Road, both from North West England ${ }^{1}$. The commentary reviews the problems experienced - including the limits of quantification, additivity and the weight given to time savings, discounting, distribution and equity, and accuracy of projections and poor progress against policy goals. As an alternative, principles are given for a participatory MCA approach for use in transport appraisal - whereby potential transport projects could be discussed by multiple actors, and estimated project impacts assessed relative to local policy criteria. This type of approach could potentially contribute to a strengthened communicative approach in decision-making (drawing on Stirling, 2006, Macharis, 2007, Macharis et al., 2010, Dimitriou et al., 2012, Leleur, 2012). The paper argues for a strengthened critical debate on the use of CBA in transport appraisal, suggesting that there is too little discussion on the fundamentals of transport appraisal and, instead, only a continual refinement of approaches within broadly the same framework.

\section{Application of CBA: Incomplete Costs and Benefits}

In historical terms, CBA can be traced back to the French engineer Jules Dupuit in the midnineteenth century, but the basis for the approach is developed from Jeremy Bentham and his concept of Utilitarianism. The best moral action is viewed as the one that maximises utility, i.e. achieves the greatest happiness of the greatest number (Bentham, 1776, Van Wee and Roeser, 2013). As Rawls (1971, p.20) explains: "the main idea is that society is ordered, and therefore just, when its major institutions are arranged to achieve the greatest net balance of satisfaction summed over all the individuals belonging to it." Utilitarianism is viewed as a problematic basis for government decision-making on a number of levels, with concerns over welfarism (results should be judged entirely by utility, i.e. the use for individuals or society), consequentialism (the rightness of actions should be judged entirely by the results), and sum-ranking (the aggregate total of utility is the criterion for judgement) (Neuburger and Fraser, 1993).

\footnotetext{
${ }^{1}$ The analysis in the paper draws from the Sintropher project (UCL, 2009-16, for the EU INTERREG IVB programme). The Fylde Coast is one of five demonstration case studies in the Sintropher project, the others being North Hesse (Germany); Valenciennes (France); West Flanders (Belgium); and Nijmegen-Kleve (the Netherlands). The South Fylde Line public transport options were considered in Sintropher, whilst the Heysham-M6 Road Link is added as a highway project comparator. The projects are not given as typical projects, but instead to provide illustrations of transport appraisal and the use of CBA in practice.
} 
The timeline of the use of CBA is well documented: first being applied in the 1930s in the USA to prioritise between flood prevention projects (Næss, 2006). The application of CBA has grown tremendously as the number of infrastructure projects and level of public sector spending has risen. CBA is now applied to a wide range of projects and policy interventions in different domains, and involves a range of different approaches, including cost-benefit analysis, cost-effectiveness analysis (measuring the progress against objectives as well as the costs) and cost-utility analysis (output is measured in one dimension, e.g. quality adjusted life years). In the UK, CBA was first used in transport planning to prioritise between proposed highway schemes, but has since been applied to public transport, cycling, walking, public realm and other projects. The CBA is used as part of the wider MCA to help decide whether a project is suitable for investment, and usually a positive BCR is required for funding. There is evidence that the $B C R$ is sometimes overlooked when appraising major infrastructure projects (Annema, 2013) and even road investments (Nellthorp and Mackie, 2000, Odeck, 2010), yet the CBA is still an important element in the decision making for the majority of transport projects in the UK.

When applying CBA in practice, there is an assumption of completeness - that the CBA covers all relevant issues and that consequences can be identified and estimated (Sen, 2000). However, the estimation of both costs and benefits are often problematic in transport projects, particularly where the projects are large and complex, and where there are multiple factors involved with the estimated impacts of investment. The coverage of issues and monetisation of costs and benefits becomes partial and hence the resulting BCR becomes unreliable (see Figure 1). Ackerman and Heinzerling (2004, p.207) have labelled the practice of CBA as "complete cost - incomplete benefit analysis". This underestimates the difficulties with some transport projects, as the partiality can occur on both sides of the equation. For example, impacts on the environmental and social and human costs and benefits can be difficult to quantify - there is a problem in trying to quantify issues that cannot easily be quantified. Hence, we would argue that complex transport projects often lead to incomplete cost - incomplete benefit analysis.

Where impacts cannot be monetised or quantified, they are often given less weight in the MCA - the quantitative evidence is given precedence - hence the MCA is weakly applied, in particular the Strategic Case. Of course, the alternative approaches to appraisal can suffer from similar quantification issues - social impact assessment (SIA), environmental impact assessment (EIA), and indeed MCA, can all suffer from incompleteness if there is a reliance on purely quantitative data. Self $(1970$, p.255, p.260) encapsulates the problems with the use of CBA: "Many of the judgements relative to the appraisal (and calculation of the likely impacts) of a transport infrastructure project can only be reasonably expressed and argued in fairly broad terms [...] they belong to the arena of public debate - and not to a world of endlessly hypothecated and quantified sums [...] ultimately, they can only be taken through a series of policy judgements, which should be as open and explicit as possible, and supported by relevant information which by itself can never be conclusive. Greater rationality in the final decision is not helped, but hindered, by the use of notional monetary figures which either conceal relevant policy judgements or involve unrealistic and artificial degrees of precision. Those who suppose otherwise are heading for a peculiarly dreary version of 1984".

Others take a more conspiratorial tone, questioning why the process is usually inaccessible to everyone but the transport economists and specialists in the field. Ackerman and Heinzerling (2004) suggest that this allows analysts, and also the politicians, to hide their vested interests behind a supposed technical debate. The process is viewed as encouraging the deregulatory agenda under the guise of scientific objectivity. Næss (2016) similarly views the use of CBA in transport as an inaccurate and biased process, favouring highway projects over others. 
Figure 1 outlines the impacts that are used in the WebTAG Appraisal Summary Table (Department for Transport, 2014a). It can be seen that the BCR is mainly a function of benefits to non-business users (commuter trips, measured in estimated time savings) and business users (journeys undertaken during work, again in time savings), versus often poorly quantified estimates of social impacts (commuting, accidents, physical activity and journey quality) and environmental impacts (such as noise, air quality, greenhouse gas emissions). Many other important impacts are seen as being monetisable, but to a less 'robust' degree (such as reliability impacts, regeneration, wider impacts, option values and landscape), and hence are not used in the CBA. There are also wider impacts that are viewed as not being capable of being monetised, presumably as yet (such as townscape, historic environment, biodiversity, etc.). These issues, and others, are sometimes incorporated in the wider MCA. In projects where the unquantified issues are important policy goals, then the BCR is partial and, we would argue, fairly meaningless. As a result, the process prioritises the projects that perform well in terms of estimated time savings, and these tend to be highway schemes and/or projects in the large urban areas - hence the accusations of bias.

The AST provides an assessment against wider criteria and is broadly representative of the concept of sustainability as three pillars, with economic, social and environmental objectives (Giddings et al., 2002). The weakness of this interpretation of sustainability is that there is often no strategy or project that satisfies all criteria - and then the economic objective is given priority at the expense of others (Hickman, 2018). In addition, the assessment of transport projects against a common set of national criteria, as set out in WebTAG, means that local projects are not assessed against local policy objectives - which feasibly may differ quite considerably by context.

Figure 1: Incomplete Cost - Incomplete Benefit Analysis for Complex Transport Projects

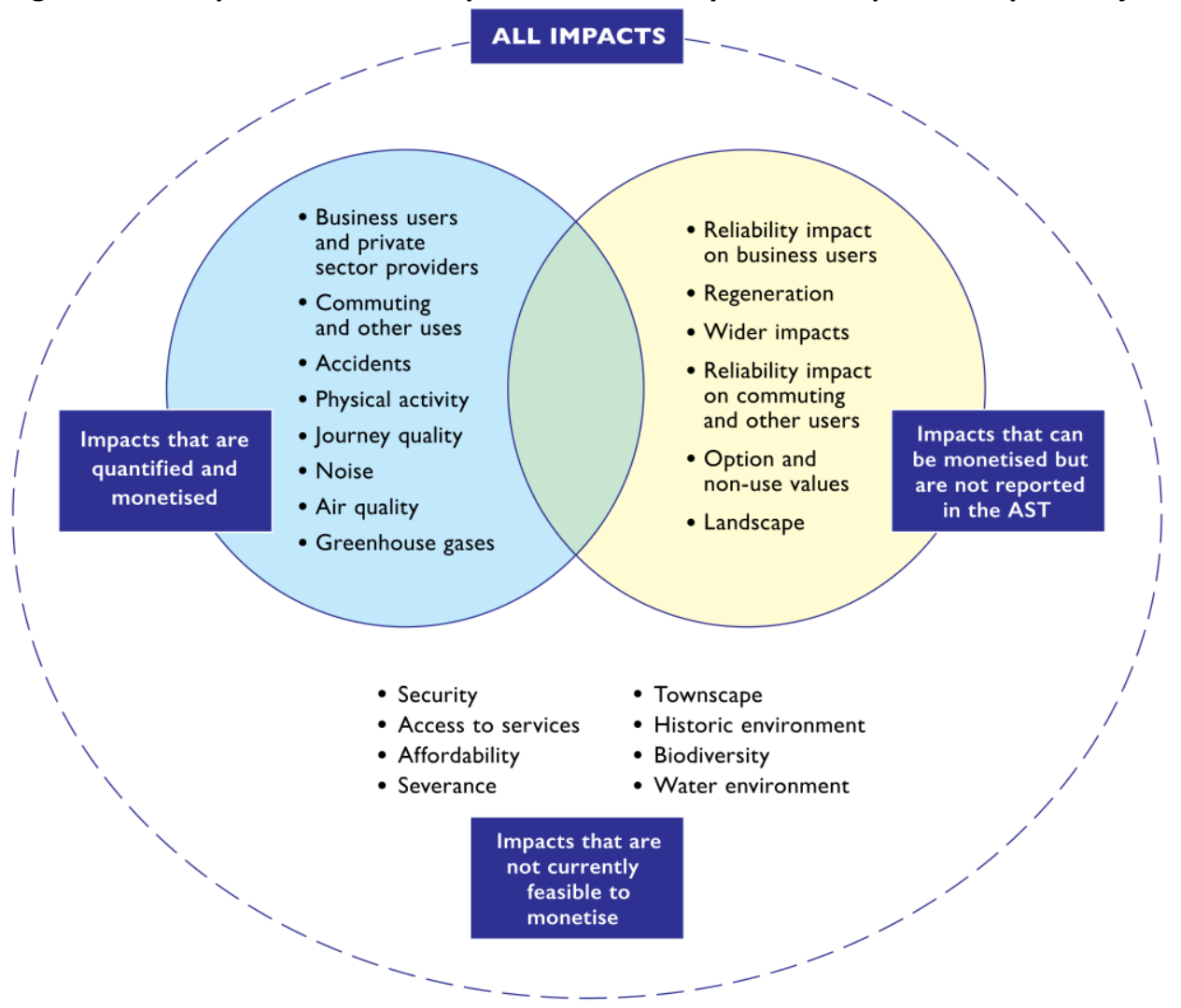

-What if the issues not captured in the CBA are important?

- Should impacts be traded off against each other?

- Should different actor views matter - including political and public acceptability? 
Many involved in performing transport appraisals perceive that the most important impacts are being captured, and that over time more and more impacts should become capable of being monetised. The onus is therefore on incorporating as many factors as possible within the CBA. The BCR is usually critical to the progression of a scheme in the UK, with project ratios in excess of 4:1 classified as 'very high' value for money; those between 4-2:1 as 'high'; 2 to 1.5:1 as 'medium'; and between 1.5 and 1:1 as 'low' - suggesting, too strongly, that the final BCR can give the answer without too much consideration of wider issues. Schemes with BCRs below 1:1 are classified as 'poor'. Only those schemes over the 2:1 threshold are likely to gain funding (Worsley, 2014). There are a few well known projects which have gone on to be funded where there were relatively low initial BCRs, such as the Jubilee Line Extension and Crossrail in London. In the case of Crossrail, 'agglomeration' factors were subsequently added to allow much improved results. The process was changed to provide a different result - the BCR increased from 1.8 (with the transport analysis) to 2.6 (with the transport and the wider economic benefits). In other cases, a low BCR has been ignored, and projects were justified for other policy and/or political reasoning (Banister, 2007, Jones, 2015). However, these are relatively rare occurrences and, usually, a good BCR is required.

The use of the common monetary standard within CBA is very attractive to decision makers, meaning that all projects can be considered and assessed relative to each other, even across modes and contexts, with the evidence summarised clearly as one ratio. If decisions are taken in a centralised manner, say at the national level as in the UK, this is an important feature, as there are many projects to be considered, and the level of local knowledge is limited. A common view is that only the benefits are likely to be underestimated, hence if the BCR is over 1:1, or ideally higher, then the project will only become more economically efficient if further impacts can be identified. This has been the case with agglomeration impacts (Department for Transport, 2014b) and regeneration impacts, where additional benefits are sometimes estimated and added into the CBA process (Department for Transport, 2014c, Smith and Hickman, 2015).

\section{Case Studies: Comparing the South Fylde Line Electrification and Heysham-M6 Link Road}

Two case studies are used to examine the use of CBA in practice. The case study approach is used to illustrate the issues found in practice and to give a detailed, nuanced examination of the cases (Flyvbjerg, 2011). The first example is the South Fylde Line electrification project, which aims to provide better connections to the south-east of Blackpool, through the Fylde Coast and onto Preston. A number of options have been appraised (Jacobs, 2015) - the main possibilities are electrification of the existing rail line, tram extension, or tram-train. All of these would provide additional public transport capacity along an under-invested line, replace the very old rolling stock (30-year old Pacer trains), and also provide improved accessibility to areas for redevelopment and regeneration in South Blackpool. The Fylde Coast sub-region is made up of Blackpool, Fylde and Wyre, with a population of 328,800 for the Fylde Coast sub-region and 142,700 in Blackpool. The region has a varied income profile, with areas of high income in Lytham St Annes. Blackpool has high levels of deprivation and has been labelled as 'England's most deprived seaside town' (BBC News, 2013); with the wards of Claremont, Talbot and Bloomfield experiencing unemployment levels at over 10 per cent (Office for National Statistics, 2013). Justifying public transport investment in deprived contexts such as Blackpool is difficult, as there are few user or non-user benefits to be demonstrated.

The two investment options considered for the South Fylde Line are: first, a proposed tram extension from the existing Blackpool tram route, extending along the South Fylde coast to terminate at Lytham. A central corridor is taken near Blackpool South station rather than along the coast, and interchange is made with Heavy Rail at Lytham, onto Preston, Manchester and beyond. Second, a tram-train running along the South Fylde line, which allows uninterrupted connections 
between Blackpool and Preston, and potentially to Manchester and beyond. The central corridor would again be taken, and the tram-train would run on street within Blackpool (Figure 2).

\section{Figure 2: The South Fylde Line Electrification Project}

A. Tram extension from the existing Blackpool tram route, extending along the South Fylde coast to terminate at Lytham (Option 1)

B. Tram-train running along the South Fylde line, allowing uninterrupted connections between Blackpool and Preston (Option 2)

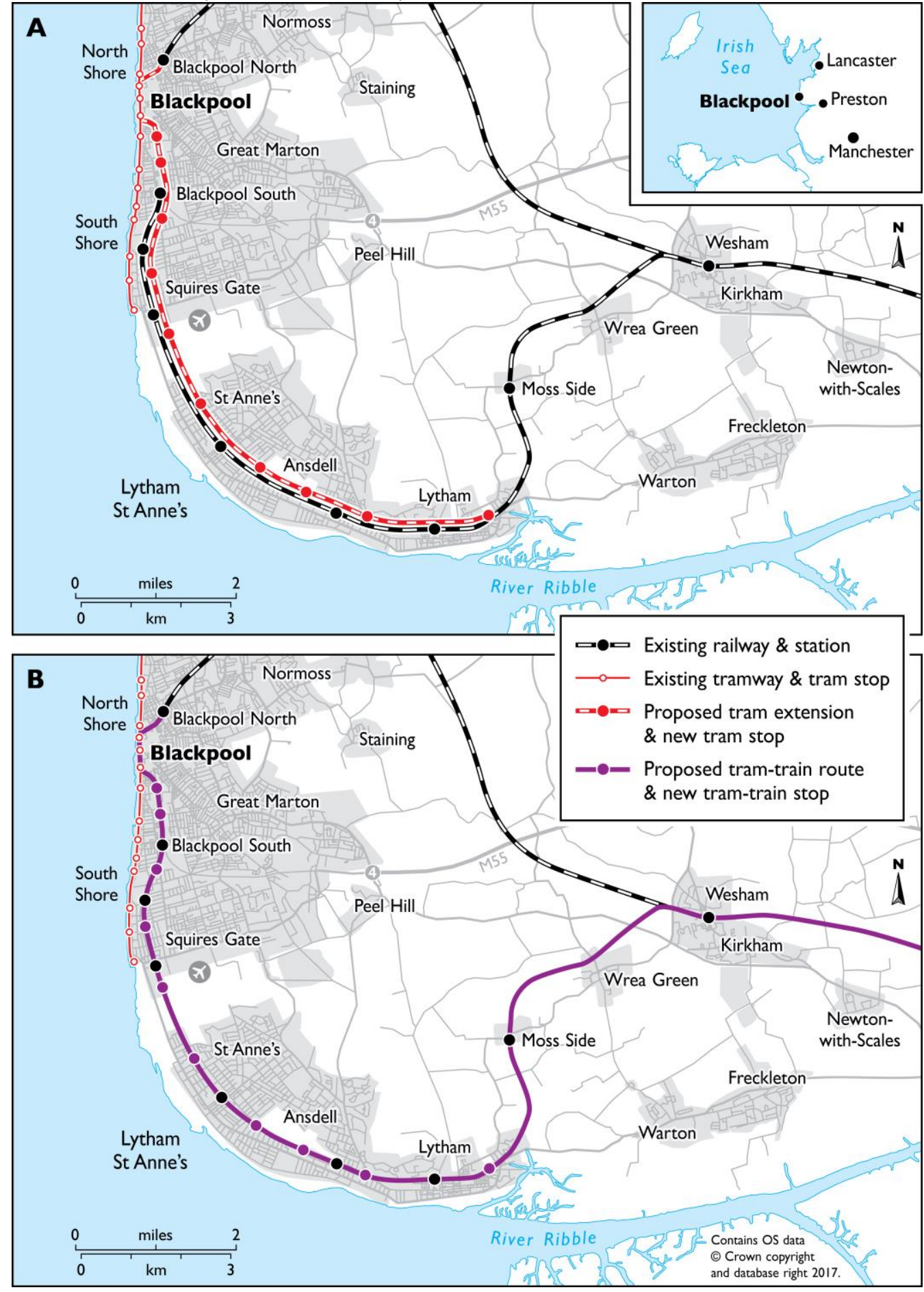

(Based on Jacobs, 2015, Dean et al., 2018)

The second project is the Heysham-M6 Link Road (Mouchel, 2011) (Figure 3), known as the Bay Gateway. The link road bypasses the north of Lancaster, connecting Heysham and Morecambe to 
Junction 34 of the M6. Lancaster has a population of 45,952; the wider conurbation, including Morecambe and Heysham, has a population of 138,375 . The link road will be a $4.8 \mathrm{~km}$ dual carriageway, also with a park and ride site at Junction 34 . The route has been planned for many years, originally identified in the 'Road Plan for Lancashire' in 1948, and the first phase was completed in July 1994 (Heysham-Morecambe). The main stated objectives are to provide improved access for residents, businesses and tourists to the Heysham and Morecambe area, to 'open up' areas for redevelopment, and to reduce congestion currently experienced within Lancaster. The Secretary of State for Transport granted full approval for the project in 2013, following a five-week public inquiry in 2007. The road opened to traffic in 2016. Lancaster, in particular, has much higher income levels and lower levels of deprivation than Blackpool. The 2010 Index of Multiple Deprivation (IMD) ranks Blackpool as the 6th most deprived local authority area in the country; whilst Lancaster is ranked at 116 out of 326 English local authorities (Lancashire County Council, 2011).

Figure 3: The Heysham-M6 Link Road (Project 3)

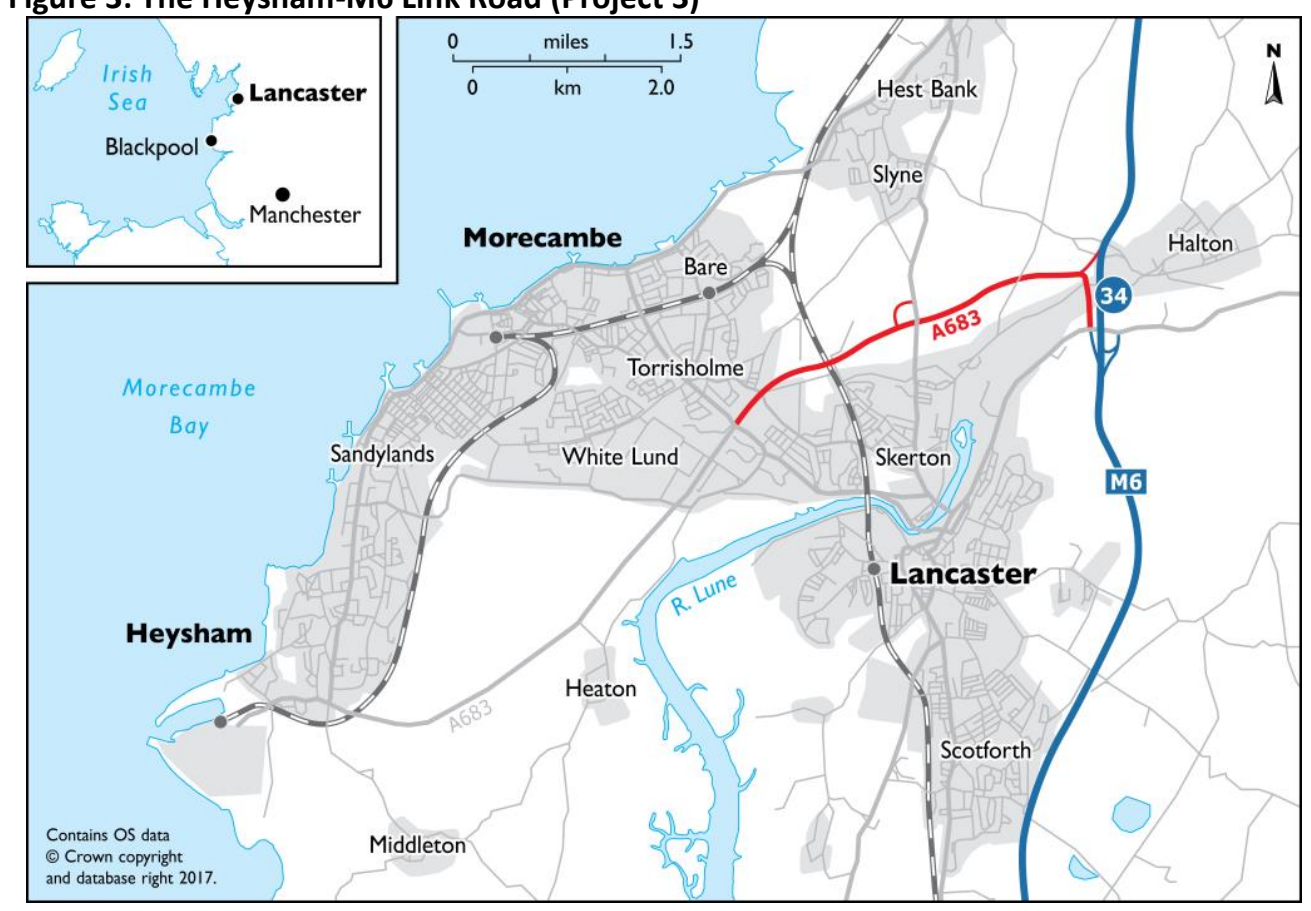

(Based on Mouchel, 2011)

\section{CBA in Practice: Examining the Components of the CBA}

Table 1 gives the results from the CBAs for the case study projects, with two modelled variants (fixed and variable demand) presented for the Heysham-M6 Link. The numbers are based on a range of assumptions that can be framed in different ways and the weighting and balance of the components of the costs and benefits are not always as might be expected. The 'economic efficiency' of the project, and ultimate value for money judgement, is represented through the net present value (NPV) and BCR. 'Benefits' include consumer user benefits, business user benefits, indirect tax revenue, accident reduction, and also carbon benefits (which are usually negative for road projects) and delays during construction (also negative). 'Costs' include investment project costs and operating costs. 
Table 1 Economic Appraisal Results

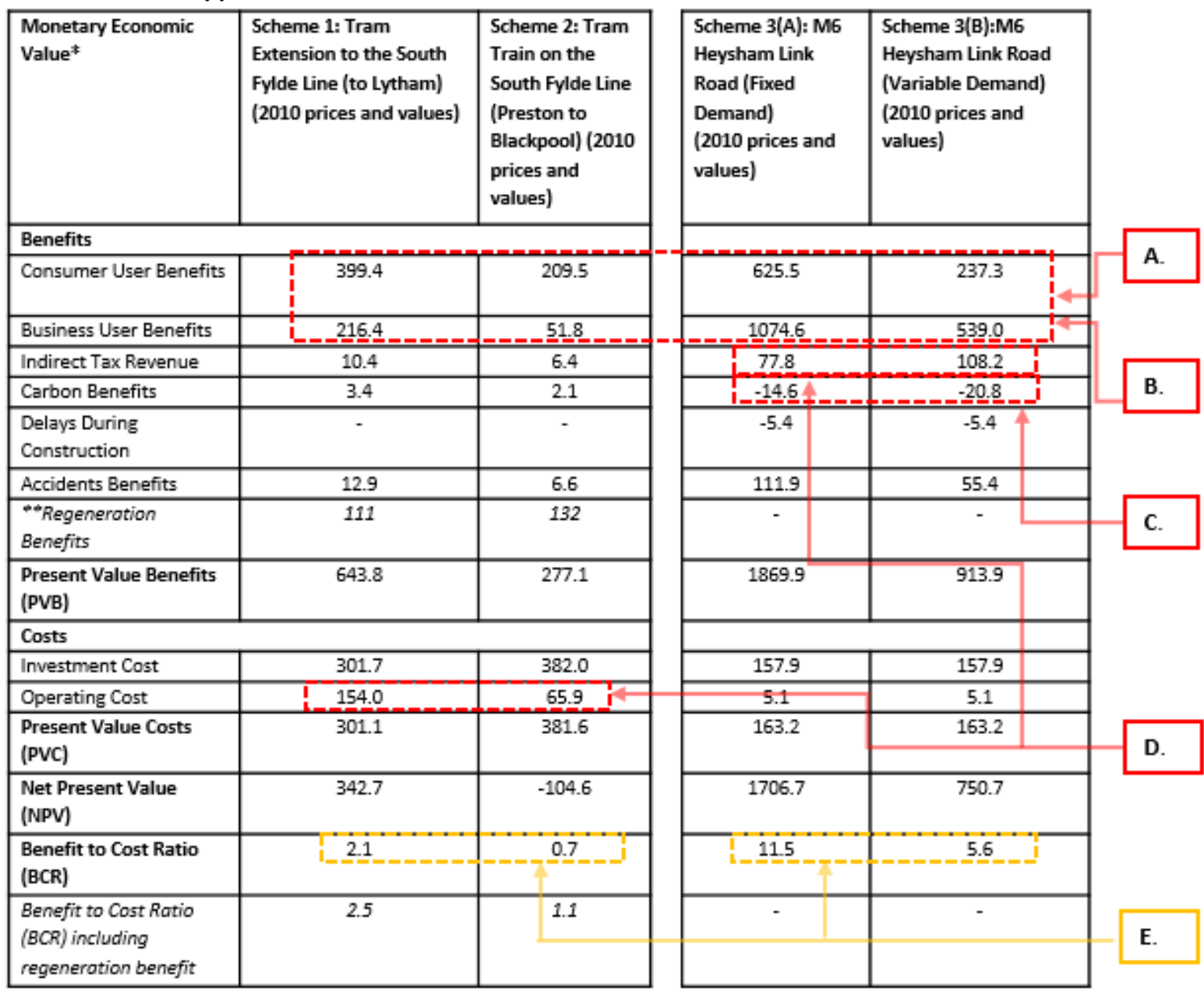

*Monetary values in $\mathrm{fm}$, all in 2010 prices. Heysham Link Road 2002 prices converted to 2010 prices.

Consumer user benefits refer to users who are not on business trips, for example commuting and shopping; business user benefits refer to users travelling on business trips or travelling between workplaces on working time; investment costs refer to construction, maintenance and land costs.

**Regeneration benefits are calculated by Jacobs (2015) assuming Gross Value Added from development surrounding the tram and tram-train upgrades.

(Mouchel, 2011, Jacobs, 2015).

The following points are made relative to the components of the CBAs:

A. There is only a narrow selection of issues that go into the CBA - time savings are almost always the most significant benefit. For most projects, the consumer users (commuting, shopping) and business users (travel during work) make up over 80 per cent of the estimated benefits - hence appraisal is really only comparing time savings relative to cost. For the Heysham-M6 Link, business user benefits account for 57.5 per cent of estimated PVB, whilst the aggregate consumer and user benefits account for 90.9 per cent of PVB. All the other issues are of marginal interest in terms of scale of impact. For the Heysham-M6 Link, accident 'benefits' provide a surprisingly positive impact - the modelling estimating that traffic will run more smoothly, hence there will be less accidents. This and other assumptions can be disputed - many would argue that the increased traffic levels are likely to lead to increased accident rates.

B. The major estimated benefits for both of the public transport options are consumer and business user benefits, accounting for 95 per cent of estimated PVB for Option 1 and 94 per cent for Option 2. Again, the projects are assessed largely in terms of time savings relative to 
cost, rather than wider impacts such as the environmental and social benefits of more people using public transport.

C. The scale of benefit given to time savings subsumes all other impacts. For example, the carbon dioxide ( $\mathrm{CO} 2$ ) benefits account for just 0.5 per cent and 0.8 per cent of the respective public transport scheme PVBs. This seems a very small estimate for a new public transport scheme that will lead to some mode shift and reduced car usage. This figure is little different in scale to the delays during construction ( 0.3 per cent of PVB). The increased levels of traffic associated with the highway scheme lead to increased $\mathrm{CO} 2$ emissions, but still they are only very marginal in scale, accounting for -2.0 per cent of benefits (costs) at most. The scale of the different components can hence be further debated.

D. Two additional factors appear to favour investment in highway projects. There are operating costs for public transport projects which far outweigh vehicle operating costs associated with road projects. Also indirect tax revenue is much higher for road projects than for public transport projects.

E. In the end, the BCR for the Heysham-M6 Link is very high, at 11.5 , reflecting relatively low investment costs, a third of the cost of the public transport schemes, and high estimated time savings. The BCR for the Heysham-M6 Link reduces to 5.6 under the variable demand model, mainly due to a reduction in estimated time savings. Many highway schemes are not assessed with variable trip matrices, hence overestimate the benefits. For example, the Heysham-M6 analysis reduces the time savings benefits by 54 per cent when using a variable demand approach. Both public transport schemes have relatively low BCRs, at 2.1 and 0.7 , reflecting high investment and operating costs, and only rise slightly if an estimation of regeneration impacts is added.

\section{Discussion: The Weaknesses of CBA}

Five key problematic areas for CBA are further discussed below in relation to the case studies.

\subsection{The limits of quantification}

The problems of quantification are clearly illustrated as many of the expected impacts of the projects are not included in the CBA, or are given marginal importance, such as the impact on the planning and development of the urban areas and surrounds, on landscape, safety and other social issues. CBA 'attempts the impossible' (Adams, 1994, Næss, 2006, Næss, 2016), in that all issues cannot be quantified or monetised, and many issues remain unquantifiable. These 'intangibles' are sometimes very important in the local context, particularly where many of the impacts are indirect and difficult to estimate. The South Fylde Line and Heysham-M6 schemes are judged, for the most part, in terms of consumer and business user benefits (time savings) against investment and operating costs - time savings representing around 90 per cent of the estimated benefit within the CBA for the projects. If wider impacts are estimated, these are often derived from 'willingness to pay' or 'revealed preference' exercises, to give monetised figures. These market-driven approaches, reflecting what an individual may wish to pay, assume that a monetary cost can be attributed to issues such as the quality and loss of open space, a landscape feature, or even the loss of life. There is great variation in the values given internationally, for example, in the UK, a fatality is given a value of $£ 1.65$ million; $€ 2.7$ million ( $€ 2.15$ million) in the Netherlands; and $\$ 9.1$ million ( $€ 5.82$ million) ${ }^{2}$ in the US (Mackie et al., 2014). These figures use the value of a 'statistical life', based on the value of risk reductions in populations and stated or revealed preferences. Sometimes lifetime earnings are used to represent the value of life. Placing a value on human life of other such impacts is highly contentious - there is no price which anyone would contemplate selling their own life. Such practice is morally unacceptable to many, and even invites ridicule (Neuburger and Fraser, 1993, Ackerman and Heinzerling, 2004). Establishing a price does not mean that lives, environment or social assets should continue to be lost or degraded. Any outstanding issues that remain unmonetisable within

\footnotetext{
${ }^{2}$ Using currency conversion rates on 16 December, 2014.
} 
the CBA are handled in a qualitative manner and presented through the MCA. However, it is the headline BCR which often drives the decision, hence many environmental, social equity and regeneration impacts are in effect overlooked in the final decision.

Finally, the CBA doesn't help us assess whether a potential project is popular or highly controversial There is no way of incorporating this type of issue in the CBA, and even not usually in the MCA. But these issues are important in decision making, to the public and politicians. For a peripheral, sociallydeprived area such as Blackpool, the case for investment in public transport is very difficult to make, in part due to the incompleteness of the CBA. It can be suggested that CBA is not supposed to cover all of these issues, that it is simply a tool to measure economic efficiency; and that it is quite difficult to address different objectives (economic and wider) within a single analytical tool. Transport appraisal practices entail the systematic employment of a large variety of evaluation techniques beside CBA, with each presenting a specific focus. Yet, we would argue, that this standpoint is problematic because of the weight given to CBA in many decisions. Giving too much weight to a partial CBA leads to a heavy bias in investment towards particular projects and areas.

\subsection{Additivity and weight given to time savings}

The additivity principle used in CBA, where net benefits are estimated across multiple costs and benefits, is contested (Sen, 2000). This utility (profit) maximising approach involves trading off one factor (such as time savings) against another (such as environmental or social impacts) (Ackerman and Heinzerling, 2004). A project is considered beneficial if there are enough time savings to outweigh the negative environmental and/or social impacts. This problem of aggregation offsets many adverse impacts, particularly if they are given little weight in the analysis. 'Allowable' adverse impacts are assumed to be the sum total of society's willingness-to-pay, aggregating individual perceptions, which again vary markedly, reflecting income levels, attitudes, and other issues (Ackerman and Heinzerling, 2004).

The main argument for transportation investments is conventionally given through the 'direct' transport benefits (see, for example, Banister and Berechman, 2001). The wider economic or other 'secondary' impacts may be perceived as more important to stakeholders, the public and politicians. The direct transport impact is measured mostly in terms of time savings, yet reducing time savings is not a direct policy objective in most contexts, more an indirect reflection of economic 'efficiency' objectives (Metz, 2008). The usual practice is to estimate the length of time 'saved' under the proposed project, relative to the reference case (which again is a projection based on assumptions), and to multiply by the number of travellers affected. For example, in public transport projects considered, user benefits comprise in vehicle time, walking time, waiting time and boarding and interchange penalties (Department for Transport, 2009). Time savings are usually estimated using a transport model and an annual user benefit calculated. There are many difficulties in applying this approach. There is little evidence that time savings are actually realised, i.e. it is simply assumed that the time released is used for productive activities (Metz, 2008). The aggregation of tiny increments of time savings is difficult to justify. In Germany, a 30 per cent discount is given to road travel time savings below 5 minutes (Mackie et al., 2014), but this is not used in the UK.

The time savings for the public transport options are of a significantly smaller scale than for the highway project. It seems much more difficult to justify public transport projects using the concept of time savings, presumably as public transport has more limited catchments via stations. A review of projects shows highway projects have consistently higher BCRs relative to public transport projects (Dodgson, 2009), hence there is concern that this is not an appropriate metric to be using, leading to some bias towards highway investment. The estimation of time savings is a proxy for quite complicated behavioural choices made relative to the scope and quality of the infrastructure and service offered and also wider issues. The assumption that time savings are related to working time 
productivity, or travel behaviour change and spatial change, are all contested. In particular, the use of travel time savings as a 'benefit' does not always apply for public transport, cycling or walking journeys, where the experience of travel, including the potential for work productivity, accessing entertainment, the level of exercise, and the status or attitude to travel may be much more important. Indeed the improved experience of travel can mean that lengthier journeys allow more work or access to entertainment to be carried out (Jain and Lyons, 2007, Hickman et al., 2015).

There are also major concerns over wider behavioural responses to new infrastructure, such as induced travel effects, which are not included in many studies. The Heysham-M6 Link Road scheme shows the large difference in the CBA in using a variable demand approach. There is a long history of evidence concerning the traffic generation effect of road capacity increases (such as Standing Advisory Committee on Trunk Road Assessment (SACTRA), 1994, Hills, 1996, Mogridge, 1997, Noland and Lem, 2002). This suggests there is an overestimation of time saving benefits in congested regions and underestimation of environmental and safety impacts if variable demand is not considered.

\subsection{Discounting}

The practice of discounting, which is fundamental to all CBAs, involves reducing the costs of impacts expected in the future. The reason for discounting is that it is expected that society will be wealthier and be able to afford costs more easily in the future. Interest can be earned on current money, hence the future unit has to be discounted to make it equivalent to the current unit (Brent, 2006). In addition, there is an opportunity cost to spending money now and a perceived desire to enjoy benefits now, rather than in the future. Hence there can be a potential difference concerning discounting costs and benefits. An annual flow of costs and benefits is usually estimated with costs reduced to their present value.

There is much debate on the practice of discounting, particularly when applied to environmental issues and social issues. A problem is that impacts occurring in the future, say 30 years hence or more, gain negligible weighting in the present day calculation (Rietveld, 2013). They rarely offset the time savings values or change the project result. For example, in the UK, the discount rate is set at 3.5 per cent annually for transport projects (HM Treasury, 2003); practice varies internationally according to the rate used, including much higher rates (Mackie et al., 2014). In the Blackpool and Heysham-M6 Link CBAs, a discount rate of 3.5 per cent per annum is used for the first 30 years of the appraisal period, and then 3 per cent thereafter. If we assume that there is a $f 1$ billion cost to mitigating climate change problems in 60 years' time, such as responding to flooding problems in North West England. This results in a cost of $£ 146.8$ million in the present value calculation in the CBA when discounted. Relative to an estimated consumer or business user benefit, this becomes a marginal issue - only the future issues are discounted. Further, if a road scheme is built, there is no estimation of the ongoing, additional requirements for road building, such as a suburban bypass leading over time to dispersed development and a requirement for further road capacity in future years.

Hence, it can be argued that large environmental and social costs expected in the long term are underestimated. The example CBAs illustrate this well: the scale of user benefits significantly outweighing any environmental or social costs that are valued. Indeed, many climate change problems are likely to be realised beyond the 60-year appraisal period. There is a case for not discounting long run environmental costs, but to continue discounting the shorter term costs and benefits (Stern, 2007). An alternative approach would be to assume that the sustainability concept is based on a 'nested' definition (Giddings et al., 2002), where a successful economy is also seen as being dependent on certain environmental and social objectives being met. If applied, this would 
mean that limits or thresholds of impact against particular criteria couldn't be breached (Hickman, 2017) - this would help lead to different investment decisions.

\subsection{Distributional and equity}

CBA usually overlooks issues of distribution and equity. Though the wider WebTAG AST can include distributional analysis (WebTAG Unit 4.2), this is often not carried out or influential in the final decision. CBA is usually made net across the whole population, and this is problematic where the distribution of benefits is uneven (Rietveld, 2013). Standard values are used for non-working time and safety, and no distinction is made between deaths and injuries suffered by users and non-users. It is also suggested that social distribution and equity issues are better dealt with through the welfare or taxation systems (Sugden, 1999), however there is still scope for improving appraisal to more effectively consider social impacts.

The basis for CBA is the concept of Pareto Optimality, developed by Vilfredo Pareto in the late nineteenth century, representing the 'efficient' state where it is assumed no improvement can be made to an individual's income without someone else's income falling (Ackerman and Heinzerling, 2004). The Kaldor-Hicks Test refines this, suggesting that if a decision increases the value of net benefits to society (benefits minus costs), then the winners will gain more than enough to compensate the losers for their losses. If the winners compensate the losers, then everyone is viewed as better off, and the new state is 'Pareto superior' to the old. This is contested as it favours the wealthy cohorts gaining at the expense of poorer cohorts, and indeed, in transport, usually there is no compensation mechanism used. Further, not compensating the losers is viewed as positive in economic efficiency terms as there is a reduced project cost (Ackerman and Heinzerling, 2004). For example, in the case studies considered, the main beneficiaries are the potential highway or public transport users - not the lower income groups who may not be so mobile. The costs, such as noise, severance, air quality and road casualties, often disproportionately fall on the lower income groups, but there is little effective means of compensation.

More thorough distributional analysis is rarely undertaken (Van Wee, 2012), indeed is difficult to carry out. There are problems in measuring impacts spatially and on population groups, particularly where populations may change over time; identifying those who gain or lose from interventions; measuring the value of impacts; and assessing the distributions of impacts. Regeneration benefits have been calculated for the public transport options on the South Fylde Coast (Jacobs, 2015), as an attempt to add in a potentially important impact from the project options. However, the method used in this area is emerging, and is relatively limited, based on guidance offered by the Department for Transport (2014c). Transport investments are only indirectly linked to regeneration impacts, and any regeneration is reliant on a number of wider factors, such as education and skill levels. Hence, approaches to calculate the transport contribution to regeneration are fraught with difficulties. There is no attempt to appraise further factors, such as consistency with urban planning; impacts on urban design, townscape, social inclusion and cohesion, within the CBA - issues that would be deemed as important by urban planners. Even in the emerging approaches to incorporate development impacts, all types of development tend to be viewed as 'positive'. There is little consideration of the quality of development, including issues of urban quality, urban sprawl or gentrification; and there is no mechanism for focusing development in areas where there are regeneration objectives. The consideration of development is hence very simplistic within CBA and the linkage with planning objectives is weak.

In addition, since CBA is consequential in nature, it favours projects with large estimated benefits. Projects are prioritised where there are large numbers of people affected, such as in large, economically-vibrant urban areas, relative to more dispersed, socially-deprived areas. The individual time savings may be marginal but, in aggregate, amount to large estimated benefits if there are large 
numbers of potential users. There may be other reasons for investing in public transport in more peripheral areas, or areas with deprivation problems - such as social inclusion issues, but these are difficult to represent in the CBA. The approach is to reward investment where a high benefit can be demonstrated - not to focus transport schemes where the planning benefit might be greatest. This is particularly problematic when projects are developed without a planning framework or masterplan to guide the choice of project options.

Hence it can be argued that the use of CBA reinforces existing problems of inequity and environmental damage, indeed rewards the higher income groups with new infrastructure and services. Though CBA is not to blame for inequalities in society, or the lack of redistributive mechanisms to rectify these, we would argue it should not be used to further exacerbate these problems. If viewed from the urban planning perspective, projects seem to be assessed against criteria which have little value. In contrast, authors such as Vickerman (2007) have expressed concerns that qualitative criteria may prevail over quantitative criteria. Again, we would argue that, in certain cases, this is required in transport appraisal.

\subsection{Accuracy of projections and poor progress against policy goals}

Two final concerns are raised, the first with a wide literature of its own - the accuracy of projections used within CBA and progress against policy goals over time. There is evidence to suggest that the numbers that go into the CBA are not accurate over time, affecting the quality of the BCR and decision-making. Many projects in the transport and infrastructure sector are subject to cost overrun and over-estimated project forecast demand (Hall, 1980, Wachs, 1990, Flyvbjerg et al., 2002, van Wee, 2007, Flyvbjerg, 2009, Nicolaisen and Driscoll, 2014). The do-nothing traffic projections can also be inaccurate but this is given less attention (Nicolaisen and Næss, 2015). Flyvbjerg, and others, suggest that this is the result of methodological and modelling shortcomings, but also systematic bias - where the project promoters provide evidence to ensure that their projects go ahead. A response within the appraisal process has been to include a major contingency factor - an 'optimism bias' of around 40 per cent of project costs. This contingency however only applies to project costs, and also seems to lead to some unexpected behavioural responses - contractors use the contingency, hence leading to more expensive projects.

There is very limited ex-post (after the fact) monitoring of transport projects - hence, as a transport profession, there is too little learning from experience on the practice and application of CBAs. Many economic assessments are prepared by consultants, and not widely published for commercial reasons. Hence, it can be very difficult to develop an evidence base of practice and to learn lessons from comparative and ex-post analysis. Sensitivity analysis is often used to help consider issues of uncertainty and there are emerging approaches to include elements of risk in project appraisal (Barfod and Salling, 2015), yet the latter are only beginning to be developed, and not used widely in practice. The quality of the appraisal process depends ultimately on the reliability of projections, and perhaps these provide an unreliable basis for decision making. In the end, there is little progress against important policy goals - on climate change, social equity, and in developing attractive urban areas.

\section{An Alternative Approach: Strengthened Participatory MCA?}

The critique is, of course, of little use if no alternative approach can be put forward. Many people recognise the problems involved in the application of CBA, but there is a difficulty in formulating a better process for project appraisal. We argue that participatory MCA approaches offer great possibilities (drawing on Stirling, 2006, Macharis, 2007, Macharis et al., 2010, Dimitriou et al., 2012, Leleur, 2012), allowing impacts to be assessed against multiple criteria, the intangible factors to be incorporated, and wider actor views to be incorporated in the process. Following Self (1970) we can see that many of the judgements required in transport appraisal can only be reasonably expressed in 
fairly broad terms - and this requires debate. The additive problem can also be overcome in that there does not need to be a crude process of addition across criteria. The following participatory MCA process is suggested, and run using a series of workshops, depending on the context (after Macharis, 2007, Leleur, 2012, and developed in Dean et al., 2018):

1. Multiple policy objectives and criteria are developed to match local policy requirements.

2. Criteria indicators are developed to understand what evidence is required to help make the impact assessment.

3. Criteria are weighted, by stakeholder groups, to prioritise important policy objectives.

4. Impacts are assessed, by stakeholder groups, through the scoring of the different scheme options against multiple criteria. Individual assessment studies, covering economic, environmental and social issues, can help inform the impact assessment.

5. A final debate covers different stakeholder views, perhaps using a final decision workshopthe varied actors will have different views on criteria and impacts. The MCA process is hence used to facilitate a public policy debate on policy criteria, weighting and impacts. The local authority makes the final decision on funding prioritisation, particularly where a consensus is not reached.

There are some potential difficulties in the MCA process too. The problems of quantification are still evident in many MCA approaches, as scoring can be carried out in a numeric manner similar to monetisation. There are issues concerning application of a participatory MCA process: criteria choice and weighting can be subjective; and impact scores are based on the performance profile of an option, which is turn is based on the result of other appraisal studies, perhaps including CBA. A process with a large number of steps and stakeholders is not feasible for all projects and can be costly - hence there may need to be some simplification for smaller projects. Involving only a few groups may exacerbate power imbalances between stakeholders and result in problems of legitimacy. In making the final decision, there will always be differences between weights and scores given by different stakeholder groups, which are difficult to resolve through debate and dialogue. Taking the mathematical average between the different scores and weights continues to be problematic - it should be the debate that leads to the final decision. All of the potential approaches to appraising transport projects therefore have some problems in application. However, perhaps MCA can be applied in a way that allows quantitative and qualitative data to be examined against wide-ranging policy criteria, and weighted according to different actor views (Dean et al., 2018).

The decision-making process can develop beyond the expert-led desktop exercise, including wider evidence gathering and public debate. Borrowing from the tradition of communicative rationality (Habermas, 1981, Dryzek, 1990, Neuburger and Fraser, 1993), the process can become much more discursive, enabling a debate over a wider range of impact criteria, weightings, and impact analysis. This will be easier for projects funded and developed at the local level; and more difficult for the national projects, where there are a range of different impacts over different geographical areas. The Swiss approach in using referendums to discuss major infrastructure investments and other policy decisions shows a potential way forward, leading to a much enhanced public debate and level of awareness on public policy - a stronger process than the Public Inquiry process used in the UK, which has only selected participants. Of course, the public need to be well informed, and there is an imperative to ensure there is a deliberative element to the process - that the public are made aware of the range of issues and the evidence before voting. The public participation could be facilitated electronically, as well as through more traditional manual voting. It could be carried out alongside multi-actor workshops to help discuss the decision criteria and impacts. The workshops might suffice for smaller projects - the approach would need to differ by scale and context. The aim is that the discussion is open and transparent, free from domination (e.g. from the project promoters and 
others) and strategising by the actors involved - hence aiming to achieve the goals of communicative rationality.

\section{Conclusions: Moving Away from CBA?}

The transport appraisal system has been gradually developed and refined over the last few decades in the UK, with approaches focused on use of CBA, and in recent years used within an MCA framework. The process has also used to justify investment in highways projects and, more recently, public transport, walking and cycling projects. It is for the non-highway projects that the application of CBA appears to break down most fully. It is here that there is most debate on the completeness of the process, on what is included in the estimation of costs and benefits, and how the issues are valued. The assumptions made in the process are critical to the final BCR produced. For the case studies considered, the dominance of business and consumer user time savings, relative to delays, carbon dioxide emissions, casualties and project costs, does not adequately capture the benefits and costs of the potential project options. This leads to very partial calculations within the CBA. When assessed against the goals of sustainability, or in terms of consistency with the aspirations of urban planning, the main components of the CBA do not cover the appropriate criteria - they do not measure the things we care about or would like to make progress against in policy terms. We have seen that there are many problematic issues with the application of CBA - including the limits of quantification, additivity and the weight given to time savings, discounting, distribution and equity, and accuracy of projections and poor progress against policy goals. We reflect that it would be useful to test many of these concerns with other selected case studies and with a larger sample of case studies to demonstrate their wider significance. In addition, the CBA process attempts to avoid the political dimensions to decision-making; yet transport planning, as a social science dealing with human behavior, is strongly political. An approach is required where multi-dimensional impacts, and political and multi-actor judgements can be integrated into a formal appraisal process - rather than omitted or considered at the end of the process.

A participatory MCA approach might help facilitate debate and awareness - much improving the current Strategic Case within WebTAG. Additionally, the transport investment should help implement the urban planning vision, brought together within a masterplan or strategic plan. Individual projects should be consistent with the strategic direction and integrated with the spatial planning approach. Alongside, there are two possible roles for CBA. The pragmatic approach is to reduce its importance, with the BCR considered as just one criterion within a strengthened MCA. Hence, there would be a wide-ranging, integrated appraisal, with different assessment tools used according to context (Coeck and Haezendonck, 2007). This would follow the German approach to transport funding at the State (Länder) level - where a much lower 1:1 BCR is required (Gühnemann, 2013) and there needs to be a good performance against environmental and social criteria for a project to progress. Another approach would be to dispense with CBA, as too partial an exercise and too simplistic for transport projects, and to handle the decision-making process primarily through participatory MCA. Perhaps wider criteria can be added into the MCA which support investment in public transport, cycling, walking and public realm projects, such as estimation of the developmental impacts or the environmental and social gains associated with investment. For example, if development value is raised, then this can be taken away from the cost of the project and/or added to the benefit. Equally, the extent of public support can be given much greater weighting in the MCA.

A more prominent role for participatory MCA would potentially help with progress against local policy priorities. Alongside, transport funding could be more fully devolved to the regions, and the allocation of spending could be decided locally. This process is already happening to an extent through devolution, greater funding is being allocated to metropolitan authorities and even agency status for the Highways Agency means that funding decisions are being progressed outside the 
Department for Transport. These trends increase the need for a more effective Strategic Case in transport appraisal, and for this step to become more important in the appraisal process, with a much closer integration with the Economic Case. Without this, there is scope for the more devolved process to lead to strategic localised behavior, with local projects supported in an untransparent manner (Purcell, 2006).

We have seen that the application of CBA is far from an objective, technical exercise - that it reflects many assumptions made in the process. At times, it resembles "nonsense on stilts" (Self, 1970). The participatory elements of CBA are weak and non-experts find it difficult to participate in the debate there is certainly little democratic nature to the process. We would argue that the over-reliance on a partial CBA in transport appraisal has become too problematic: you get what you measure, and perhaps we are measuring (and not discussing) it in the wrong way?

Acknowledgements: thanks to the anonymous reviewers who gave very useful comments and significantly improved the paper. Thanks to Jamie Quinn for redrawing images 1-4.

\section{References}

ACKERMAN, F. 2008. Critique of Cost-Benefit Analysis, and Alternative Approaches to DecisionMaking. A report to Friends of the Earth. London: Friends of the Earth.

ACKERMAN, F. \& HEINZERLING, L. 2004. Priceless: On Knowing the Price of Everything and the Value of Nothing, New York, New Press.

ADAMS, J. 1994. The role of cost-benefit analysis in environmental debates. London: UCL [http://john-adams.co.uk/wp-content/uploads/2006/The\%20role\%20of\%20costbenefit\%20analysis\%20in\%20environmental\%20debates.pdf] [accessed February 2014].

ANNEMA, J. A. 2013. The use of CBA in decision-making on mega-projects: empirical evidence. In: PRIEMUS, H. \& VAN WEE, B. (eds.) International Handbook on Mega-Projects. Cheltenham: Edward Elgar.

BANISTER, D. 2007. Quantification of the non-transport benefits resulting from rail investment. Working Paper 1029. Oxford: Transport Studies Unit [http://www.tsu.ox.ac.uk/pubs/1029banister.pdf] [accessed March 2015].

BANISTER, D. \& BERECHMAN, Y. 2001. Transport investment and the promotion of economic growth. Journal of Transport Geography, 9, 209-218.

BARFOD, M. B. \& SALLING, K. B. 2015. A new composite decision support framework for strategic and sustainable transport appraisals. Transportation Research Part A: Policy and Practice, 72, 1-15.

BBC NEWS 2013. Blackpool is 'most deprived seaside town' [http://www.bbc.co.uk/news/ukengland-manchester-23783425].

BENTHAM, J. 1776. A Fragment on Government, London, Cosimo (2012).

BRENT, R. 2006. Applied Cost-Benefit Analysis, Cheltenham, Edward Elgar.

COECK, C. \& HAEZENDONCK, E. 2007. Conclusion: evolution towards integrated project appraisal. In: HAEZENDONCK, E. (ed.) Transport Project Evaluation. Extending the Social Cost-Benefit Approach. Cheltenham: Edward Elgar.

DEAN, M., HICKMAN, R. \& CHEN, C.-L. 2018. Testing the Effectiveness of Participatory MCA: The Case of the South Fylde Line. submitted.

DEPARTMENT FOR TRANSPORT. 2009. Website for Transport Analysis Guidance (WebTAG), TAG Unit 3.5.6, Value of Time and Operating Costs [Online] [Online]. [Accessed February 2014.

DEPARTMENT FOR TRANSPORT. 2014a. Website for Transport Analysis Guidance (WebTAG), TAG Unit A1.1, Cost-Benefit Analysis [Online]. [Accessed Accessed February 2014.

DEPARTMENT FOR TRANSPORT 2014b. Website for Transport Analysis Guidance (WebTAG), TAG Unit A2.1, Wider Impacts [Online]. [Accessed February 2014]. 
DEPARTMENT FOR TRANSPORT 2014c. Website for Transport Analysis Guidance (WebTAG), TAG Unit A2.2, Regeneration Impacts [Online]. [Accessed February 2014].

DEPARTMENT FOR TRANSPORT. 2017. Website for Transport Analysis Guidance (WebTAG) [accessed March 2017] [Online].

DIMITRIOU, H., WARD, J. \& WRIGHT, P. 2012. OMEGA Project: Summary Report. London: OMEGA Centre, UCL.

DODGSON, J. 2009. Rates of Return on Public Spending on Transport. London: RAC Foundation.

DRYZEK, J. 1990. Discursive Democracy: Politics, Policy, and Political Science, Cambridge, Cambridge University Press.

FLYVBJERG, B. 2009. Survival of the unfittest: why the worst infrastructure gets built - and what we can do about it. Oxford Review of Economic Policy, 25, 344-367.

FLYVBJERG, B. 2011. Case Study. In: DENZIN, N. \& LINCOLN, S. (eds.) The Sage Handbook of Qualitative Research. Thousand Oaks, CA: Sage.

FLYVBJERG, B., HOLM, M. \& BUHL, S. 2002. Underestimating costs in public works projects: error or lie? Journal of the American Planning Association, 68, 279-295.

GIDDINGS, B., HOPWOOD, B. \& O'BRIEN, G. 2002. Environment, economy and society: fitting them together into sustainable development. Sustainable Development, 10, 187-196.

GÜHNEMANN, A. 2013. International Comparison of Transport Appraisal Practice - Annex 2: Germany Country Report. Institute for Transport Studies, University of Leeds.

HABERMAS, J. 1981. The Theory of Communicative Action: Reason and the Rationalization of Society, Cambridge, Polity Press (1984).

HALL, P. 1980. Great Planning Disasters, London, Weidenfeld \& Nicolson.

HICKMAN, R. 2017. Sustainable travel or sustaining growth? In: COWIE, J. \& ISON, S. (eds.) The Routledge Handbook of Transport Economics. Abingdon: Routledge.

HICKMAN, R. 2018. Transport appraisal: thinking beyond the CBA? In: DOCHERTY, I. \& SHAW, J. (eds.) The Inside Track: why transport matters and how we can make it better. Bristol: Policy Press.

HICKMAN, R., CHEN, C.-L., CHOW, A. \& SAXENA, S. 2015. Improving interchanges in China: the experiential phenomenon Journal of Transport Geography, 42, 175-186.

HILLS, P. J. 1996. What is induced traffic? Transportation, 23, 5-16.

HM TREASURY 2003. The Green Book, London, TSO.

JACOBS 2015. South Fylde Rail Connectivity Study. Stage 2 Results. Preston: Lancashire County Council.

JAIN, J. \& LYONS, G. 2007. The gift of travel time. Journal of Transport Geography, 16, 81-89.

JONES, P. 2015. Assessing the wider impacts of the Jubilee Line Extension in East London. In: HICKMAN, R., GIVONI, M., BONILLA, D. \& BANISTER, D. (eds.) Handbook on Transport and Development. Cheltenham: Edward Elgar.

KORNHAUSER, L. A. 2000. On justifying cost-benefit analysis. The Journal of Legal Studies, 29, 10371057.

LANCASHIRE COUNTY COUNCIL 2011. The English Indices of Deprivation 2010. Local authority level analysis [http://www3.lancashire.gov.uk/corporate/web/?siteid=6121\&pageid=40300\&e=e] [accessed July 2015]. Preston: LCC.

LELEUR, S. 2012. Complex Strategic Choices: Applying Systemic Planning for Strategic Decision Making, London, Springer Verlag.

MACHARIS, C. 2007. Multi-criteria analysis as a tool to include stakeholders in project evaluation: the MAMCA method. In: HAEZENDONCK, E. (ed.) Transport Project Evaluation. Extending the Social-Cost Benefit Approach. Cheltenham: Edward Elgar.

MACHARIS, C., DE WITTE, A. \& TURCKSIN, L. 2010. The Multi-Actor Multi-Criteria Analysis (MAMCA) application in the Flemish long-term decision making process on mobility and logistics. Transport Policy, 17, 303-311.

MACKIE, P. \& PRESTON, J. 1998. Twenty-one sources of error and bias in transport project appraisal. Transport Policy, 5, 1-7. 
MACKIE, P., WORSLEY, T. \& ELIASSON, J. 2014. Transport appraisal revisited. Research in Transportation Economics, 47, 3-18.

METZ, D. 2008. The Myth of Travel Time Saving. Transport Reviews, 28, 321 - 336.

MOGRIDGE, M. J. H. 1997. The self-defeating nature of urban road capacity policy. A review of theories, disputes and available evidence. Transport Policy, 4, 5-23.

MOUCHEL 2011. Heysham - M6 Link Road Traffic Model. Forecasting and Economics Report. Preston: Lancashire County Council.

N/ESS, P. 2006. Cost benefit analyses of transportation investments: neither critical nor realistic. Journal of Critical Realism, 5, 32-60.

N/ESS, P. 2016. Inaccurate and biased: cost-benefit analyses of transport infrastructure projects. In: N/ESS, P. \& PRICE, L. (eds.) Crisis System: A Critical Realist and Environmental Critique of Economics and the Economy. Abingdon: Routledge.

NELLTHORP, J. \& MACKIE, P. J. 2000. The UK Roads Review-a hedonic model of decision making. Transport Policy, 7, 127-138.

NEUBURGER, H. \& FRASER, N. 1993. Economic Policy Analysis: A Rights-Based Approach, Aldershot, Ashgate.

NICOLAISEN, M. S. \& DRISCOLL, P. A. 2014. Ex-post evaluations of demand forecast accuracy: a literature review. Transport Reviews, 34, 540-557.

NICOLAISEN, M. S. \& N/ESS, P. 2015. Roads to nowhere: The accuracy of travel demand forecasts for do-nothing alternatives. Transport Policy, 37, 57-63.

NOLAND, R. \& LEM, L. 2002. A review of the evidence for induced travel and changes in transportation and environmental policy in the US and the UK. Transportation Research $D, 7$, 1-26.

ODECK, J. 2010. What determines decision-makers' preferences for road investments? Evidence from the Norwegian road sector. Transport Reviews, 30, 473-494.

OFFICE FOR NATIONAL STATISTICS 2013. Larger English seaside destinations had above average deprivation in 2010 [http://www.ons.gov.uk/ons/rel/regional-trends/area-based-analysis/aprofile-of-deprivation-in-larger-english-seaside-destinations--2007-10/sty-seasidedestinations.html].

POSNER, E. \& ADLER, M. 1999. Rethinking Cost-Benefit Analysis. John M. Olin Program in Law and Economics, Working Paper No. 72.

PREST, A. \& TURVEY, R. 1965. Cost-benefit analysis: a survey. Economic Journal, 37, 47-61.

PURCELL, M. 2006. Urban democracy and the local trap. Urban Studies, 43, 1921-1941.

RAWLS, J. 1971. A Theory of Justice, Cambridge, MA, Harvard University Press.

RIETVELD, P. 2013. Appraisal methods for transport policy. In: VAN WEE, B., ANNEMA, J. A. \& BANISTER, D. (eds.) The Transport System and Transport Policy. Cheltenham: Edward Elgar.

SELF, P. 1970. Nonsense on stilts: cost benefit analysis and the Roskill Commission. The Political Quarterly, 41, 249-260.

SEN, A. 2000. The discipline of cost-benefit analysis. Journal of Legal Studies, 29, 931-952.

SMITH, G. \& HICKMAN, R. 2015. South Fydle Connectivity Study. TPM Conference Paper. London.

STANDING ADVISORY COMMITTEE ON TRUNK ROAD ASSESSMENT (SACTRA) 1994. Trunk Roads and the Generation of Traffic. London: Department for Transport.

STERN, N. 2007. The Economics of Climate Change, Cambridge, Cambridge University Press.

STIRLING, A. 2006. Analysis, participation and power: justification and closure in participatory multicriteria analysis. Land Use Policy, 23, 95-107.

SUGDEN, R. 1999. Developing a consistent cost-benefit framework for multi-modal transport appraisal London: Department of the Environment, Transport and the Regions.

VAN WEE, B. 2007. Large infrastructure projects: a review of the quality of demand forecasts and cost estimations. Environment and Planning B: Planning and Design, 34, 611-625.

VAN WEE, B. 2012. How suitable is CBA for the ex-ante evaluation of transport projects and policies? A discussion from the perspective of ethics. Transport Policy, 19, 1-7. 
VAN WEE, B. \& ROESER, S. 2013. Ethical theories and the cost-benefit analysis-based ex ante evaluation of transport policies and plans. Transport Reviews, 33, 743-760.

VICKERMAN, R. 2007. The boundaries of Welfare Economics: Transport appraisal in the UK. In: HAEZENDONCK, E. (ed.) Transport Project Evaluation: Extending the Social Cost-Benefit Approach. Cheltenham: Edward Elgar.

WACHS, M. 1990. Ethics and advocacy in forecasting for public policy. Business \& Professional Ethics Journal, 9, 141-157.

WORSLEY, T. 2014. Developments in the appraisal of transport infrastructure investments in the UK and other European countries, and its influence on decisions. Report for EU SINTROPHER, Interreg IVB, Leeds: ITS, University of Leeds.

WORSLEY, T. \& MACKIE, P. 2015. Transport Policy, Appraisal and Decision-Making. RAC Foundation, London: Institute for Transport Studies, University of Leeds. 